\title{
A Study of How Angry Birds Has Been Used in Mathematics Education
}

\author{
Deborah Moore-Russo ${ }^{1}$ - Jeri Diletti ${ }^{1}$. \\ Joshua Strzelec ${ }^{1}$ - Caitlin Reeb ${ }^{1}$. \\ Jonathan Schillace ${ }^{1}$ - Ashley Martin ${ }^{1}$. \\ Talal Arabeyyat ${ }^{1} \cdot$ Kristen Prabucki $^{1}$. \\ Stefanie Scanlon ${ }^{1}$
}

Published online: 8 September 2015

(C) Springer International Publishing 2015

\begin{abstract}
Understanding how teachers are leveraging entertainment media for educational purposes is imperative in this age with near ubiquitous presence of digital games. In this qualitative study that considered videos posted to YouTube, we report how the digital game Angry Birds ${ }^{\circledR}$ has been implemented in a variety of settings in mathematics education. In particular we describe certain aspects the research team deemed effective and ineffective. Findings suggest that incorporation of this digital game should be done with planning and systematic organization that considers how the game can be used to explicitly connect mathematical ideas within and to the context of the game.
\end{abstract}

Keywords Video games · Digital game-based learning - Instrumental orchestration · Multiple representations · Quadratic equations · Parabolas

We are witnessing a mad rush to pour educational content into games in an ad hoc manner in hopes that player/learners are motivated simply because the content is housed inside a game. (Gunter et al. 2008, p. 511)

The US National Council of Teachers of Mathematics, in its Principles and Standards for School Mathematics (NCTM 2000), claimed that technology is essential in the teaching and learning of mathematics because it can serve as an efficient and

'Angry Birds' is a registered trademark in the US of Rovio Entertainment Ltd.

Deborah Moore-Russo

dam29@buffalo.edu

1 University at Buffalo, State University of New York, Buffalo, NY, USA 
effective means to facilitate understanding of mathematical concepts and relationships. NCTM's position was that technology can help instructors and students explore mathematical ideas deeply and in different ways than would be possible with just a chalkboard or an overhead projector. The document also clearly pointed out that technology is not a panacea for mathematics education. Similar to incorporating other tools, technology can be beneficial or detrimental to the teaching and learning of mathematics depending on how it is used.

While the vision in this document was progressive, some of the language now seems somewhat dated. Technology no longer refers solely to computers, mathematical software (e.g., dynamic geometry software platforms) or graphing calculators. Students today have many digital experiences and encounter a vast array of digital tools. Moreover, when considering the role of 'technology' in mathematics education, one could argue that the field of mathematics education has been hyperfocused on which digital tools were implemented, to what extent they were implemented, and when this implementation occurred, while missing another key issue, namely how digital tools have been used to facilitate mathematical understanding (Ball and Stacey 2005; Heid 2005; Heid and Edwards 2001; Sinclair and Crespo 2006).

Digital media have a significant presence in a large proportion of students' lives. Even though many students use them informally for entertainment, such media are also being used to supplement or enhance mathematics education in more formal settings. Even video games can be used to situate thinking and problem solving in a meaningful context, where players encounter various signs and tasks in an environment where words, images, actions, and sounds are intertwined with one another. In fact, there have been recent calls for the consideration of video games as a viable medium for learning (Devlin 2011; Federation of American Scientists 2006; Gee 2003). ${ }^{1}$ Theoretically, such efforts should combine the most powerful features of interactive multimedia design with the most effective principles of technologymediated learning. Yet Squire (2006) claims we know little about how video games are implemented in education, while Ke (2009) questions whether their incorporation into the classroom has been effective.

Since digital tools have the potential to enhance mathematics education, and most students are exposed to a variety of digital entertainment media (including video games) on a daily basis, it is not surprising that educators might try to take advantage of these digital experiences. As the trend moves towards the ubiquitous presence of digital games in the lives of children and adolescents, understanding the affordances, constraints and drawbacks of leveraging entertainment media for educational purposes is imperative. For these reasons, the research in this article focuses on a particular digital entertainment phenomenon that has been used by many to supplement educational efforts. More specifically, we will report on how the popular video game Angry Birds has been implemented in educational environments, focusing on how the game has been used as a means to help illustrate and explain mathematical ideas.

\footnotetext{
${ }^{1}$ Work around this premise has been taking place since at least the early 1990s; see, for instance, Maria Klawe's work in elementary schools using Counting on Frank and the development of E-GEMS project at the University of British Columbia.
} 


\section{Literature Review}

The sheer number of digital tools, including video games, made available since the turn of this century is staggering. Yet instructors are often expected to find ways to incorporate developing technologies and new digital tools properly into their curriculum, which might also be changing, all the while maintaining an appropriate pedagogy.

\section{Incorporating Digital Tools}

One prevailing attitude is that the incorporation of digital tools enhances classroom instruction by providing dynamic tools for exploration (Drickey 2006; Prensky 2001). Instructors might integrate digital tools into their instruction for this reason, but they could also incorporate them as a means to move away from more routine instruction to create a more student-centered, engaging learning environment.

Whether the integration of digital tools is successful depends on a number of factors. Some of them are that instructors need time to practice in order to understand the functionalities of the digital tool and they need to consider how incorporating it might impact the classroom, by altering student roles and behavior (Alagic 2003; Ketelhut and Schifter 2011; Ozel et al. 2008).

Instructors also need to understand the exact manner in which specific resources should be integrated into the curriculum, bearing in mind how they relate to class objectives and course assessments. Just because an instructor has acquired a certain set of digital skills does not mean that he or she has developed a pedagogical understanding of how to implement the related digital tool into instruction. Instructors must recognize that the addition of a digital tool brings with it a new layer of complexity to the classroom (Hoyles et al. 2004).

To accomplish the adoption of digital tools as effective pedagogical instruments, instructors should be aware of and appreciate the interrelationships among tools, students and instructional goals. It is when instructors understand these interrelationships that they are more likely to create learning experiences that utilize digital tools in ways that help students make meaningful connections to and between mathematical ideas (Chen 2011; Koehler and Mishra 2005). To be effective, digital tools must be a good fit for the task at hand and incorporated so they are interwoven in the lesson with meaningful connections to the instructional objectives (Goodhue 1995; Goodhue and Thompson 1995; Lawrenz et al. 2006). Therefore, instructors should carefully consider in what ways, when, and how to use digital tools so they understand how these particular resources might help meet educational goals, such as those related to student achievement, engagement and attitude (Clark-Wilson et al. 2014; Dewey et al. 2009).

\section{Digital Games in Education}

Digital games (a term we use interchangeably with video games) refer to digital environments that allow individuals to play games through interactions with electronic systems, known as platforms, so that the user interface allows visual (and often audio) feedback. As platforms for digital games have evolved from coin-operated arcade games to home-based and hand-held video consoles to touch-sensitive applets, the idea 
of incorporating digital games as instructional resources has become more feasible. Squire (2006) posits that instructors (and instructional developers) need "to pay closer attention to video games because they offer designed experiences, in which participants learn through a grammar of doing and being" (p. 19). In light of accessibility and potential benefits, it is not surprising that the incorporation of digital games is a relatively recent way that instructors have tried to facilitate learning so that students are able to scaffold ideas, access prior knowledge and think more deeply about the concepts being presented.

While studies (e.g., Boyan and Sherry 2011; McDaniel and Kenny 2013) have started to consider the preconceived notions instructors may have about digital game use in classrooms, there seems to be increasing support among instructors for the implementation of digital games in education. In fact, many report that they plan on incorporating games in their own instruction (Pastore and Falvo 2010). The best indicators as to whether instructors actually do implement digital games are their levels of access to the games and their beliefs about the usefulness of implementing games (Proctor and Marks 2013). However, less is known about the manner in which those instructors who chose to use digital games in their instruction actually incorporate them.

Instructors and students alike can benefit from the incorporation of digital games. Instructors can track the decisions and achievements of a student progressing in a game (Gros 2007). Digital games, when used in the classroom, have been found to increase student achievement when students and instructors are provided with an ample amount of time, training, and technical support for their implementation (Kebritchi et al. 2010; Vogel et al. 2006). Moreover, game-based educational environments have also been found to improve student attitudes along with achievement (Gillispie et al. 2010). However, there is an important caveat that should not be overlooked. The incorporation of digital games can promote learning and motivation, but only as long as students are able actively to connect the game to the educational content (Erhel and Jamet 2013). In fact, the lack of clearly specified learning outcomes, as well as time for students to reflect on their learning during and after engaging in game play, can contribute to students' conflicting attitudes to game-based instruction (Bragg 2007).

Although digital games can be used to help students think about mathematics at a deeper level, such incorporation can instead lead to the creation of a superficial knowledge base for students (Chen 2011). Not all digital games create a deeper understanding of mathematical topics nor do all students enjoy the use of these games in the classroom. For instance, students who play digital video games more often outside of class were shown to benefit more from their use in the classroom, and girls, especially those who often have less experience playing such games, may not be as motivated by their incorporation (Bourgonjon et al. 2010; Kafai et al. 2008). In short, the biggest challenge for educators looking to implement game-based learning is to create a space where students are "engaged, motivated, supported and interested [... where] learning [is] to be undertaken in relation to clear learning outcomes" (de Freitas 2006, p. 5).

\section{Theoretical Underpinnings}

Semiotics is the study of how people use "things" (i.e., semiotic resources) to represent or convey information, and how, in turn, others interpret them. Semiotic resources are 
created, selected and given meaning, sometimes unintentionally and subconsciously, by the people using them in their attempts to understand and share mathematical ideas (Moreno-Armella et al. 2008). They can be verbal utterances, inscriptions, body movements or physical (or digital) objects that are used to signify actions, ideas and relationships (Moore-Russo and Viglietti 2012; Hoopes 1991; Radford 2002). Such resources are more than simply a means for communication (Núñez et al. 1999; Radford et al. 2005); they also influence how understanding develops. In mathematics, semiotic resources tend to reflect the algebraic, geometric, numerical and verbal registers to represent ideas.

Given the set of all representations associated with the same idea, the commonality of all these representations can be considered the "mathematical object" at its core (Duval 2006). Understanding, then, is associated with a synergy or "simultaneous awareness' of the different registers used to represent a mathematical concept (McGee and Moore-Russo 2015; Duval 1999, 2006). Yet, McGee and Martinez-Planell (2014) suggest instructional designers make erroneous assumptions that students are able to make connections automatically when registers of representation are implied rather than explicitly presented.

Since this study considers the introduction of a particular type of semiotic resource, we now narrow our focus. For us, an artifact is simply a human-made (physical or digital) object or tool, whereas an instrument is an artifact for which a use has been found. An instrument cannot exist without an individual who has appropriated it for a specific purpose. Instrumental genesis (Trouche 2004) refers to the process of a tool moving from being a useless, unused artifact to becoming an useful, used instrument. This process is dependent not only on the tool itself, but also on the individual employing it (Trouche 2003), since cultural and personal history (including lived experiences and perceptions) play a role in how the person perceives and uses any tool (Noss and Hoyles 1996). While the general nature and specific characteristics an artifact offers may pre-structure the relative way that individuals interact with and consider mathematical ideas (Rabardel 2001), Clark (1983) argues that it is not only the tool itself, but rather how it is used, that impacts its effectiveness, since "the key to promoting improved learning [...] appears to lie in how effectively the medium is exploited in the teaching and learning situation" (Owston 1997, p. 29).

The instrumental genesis process is complex and is linked to the particular characteristics (including potentialities and constraints) of the tool. Moreover, tools are not always used to accomplish the purposes for which they were originally designed. How a tool is used is not simply based on the designer's original notions, but also on the user's employment and, in turn, "the user's conception of the instrument is formed through use" (Trouche 2004, p. 295). Trouche cites Rabardel (1995) using the word 'catachresis' for when an artifact is adapted and used as an instrument in a way that differs from its originally conceived purpose.

Mathematical understanding can be thought of as being: both situated and shaped by the tools being used, the users' relationship to the tools - including whether the users judge them to be expressive of their developing mathematical meanings - and ultimately whether these meanings are valued and judged by the community (e.g., the classroom) to be mathematical. (Hoyles et al. 2004, p. 314)

Since there are multiple ways that an idea can be conceptualized and communicated, the tools chosen for instructional tasks and the instructional guidelines and support 
given to students engaged in the tasks can have a considerable impact on how students come to understand mathematical ideas.

Ultimately, classroom instructors make instructional decisions, such as which digital tools to introduce, which tasks to assign and how tasks are designed, in order to take advantage of a digital tool's potential affordances and to work with its constraints and drawbacks. Instructors incorporate digital tools in classroom settings to help facilitate the learning process. However, they often fail to recognize adequately that the introduction of digital tools can disrupt normative classroom discourse, and they may not acknowledge the extent of the new demands on the students to connect the digital tool to the curriculum.

Instrumental orchestration (Trouche 2004, 2005) refers to the external steering on the part of an instructor to help students with the instrumental genesis process. Instrumental orchestration is not haphazard; it should not be left to chance but, rather, involves instructional intention and systematic organization (Drijvers et al. 2010), related to how a tool will be introduced and in which ways and for which tasks it will be used in the classroom. Trouche (2004) points out that instrumental orchestration should be a necessity; yet, it is "rarely taken into account" (p. 296).

The current study does not investigate instrumental genesis per se; rather, it focuses more on instrumental orchestration and how instructors use semiotic resources to steer students' mathematical meaning-making processes. More specifically, the study considers how instructors use Angry Birds to illustrate and explain mathematical ideas. The research questions that guided the study were:

1. Which mathematics topics are addressed by the Angry Birds game, especially by instructors and students as a part of instruction, but also more informally by individuals involved in play?

2. How is this game used in the teaching and learning of mathematics? In which ways, and for what tasks, is the game being used for instruction?

3. Which instructional practices can be judged to be effective and ineffective, by considering how instructors steer students to make mathematical meaning, when Angry Birds is incorporated in mathematics instruction?

\section{Method}

The mathematics education research team consisted of a researcher (the lead author), three doctoral students (all with at least 5 years of experience teaching mathematics) and four Master's students (all with less than 2 years of experience teaching mathematics). The research team used inductive techniques in a guided, grounded study.

\section{Data Collection}

The original Angry Birds game has been downloaded over a million times and has had at least a dozen spin-offs. Game play takes place in a variety of structures as you advance by adjusting angles to launch birds (with various abilities) from a sling-shot at egg-stealing pigs. We selected this game because of its enormous popularity across a 
wide span of ages, as well as across a number of platforms (e.g., smart phones, tablet computers).

In order to obtain a body of data for review, the research team turned to YouTube as a venue that is easily accessible and used by a large number of individuals from a variety of geographical locations, especially those who could be digitally savvy enough to have attempted (and recorded for posterity) experiences in which a digital game was used for mathematics education. The data set used for this study consisted of 54 YouTube videos (see Appendix for a listing of the urls); a posted video was the unit of analysis. In order to generate the data set, YouTube's search engine was used on July 30, 2013 for a total of 16 searches. For each, the first two search terms were the words 'angry' and 'birds', while the third search term was one of the following list: algebra, angle, arithmetic, calculus, functions, geometry, intercepts, length, math (which yielded the same results as 'maths' and 'mathematics'), measurement, parabola, parametric, pre-calculus, quadratic, trigonometry and vector. The first 20 video links that appeared in each of the 16 searches were noted. These searches yielded many of the same videos; in the end, a total of 54 distinct videos related to Angry Birds were identified for the study.

\section{Data Analysis}

Each member of the research team watched all 54 videos in their entirety at least twice, taking notes immediately after viewing each one. The research team then formed three small groups, each containing one doctoral student, which compared the notes of its individual members and created a two- to five-paragraph description summarizing the group's findings on each of the 54 videos.

At this stage, all three groups revisited each video with their descriptions to create a spreadsheet: who was in the video, how Angry Birds was used, what the intended purpose of the video seemed to be and whether the task reflected in the video met that purpose. If the video was related to formal instructional activity, the group reported: the type of classroom setting (e.g., lecture, student report), offering suggestions as to why Angry Birds might have been selected; which mathematical ideas were addressed; how mathematical learning opportunities (if they arose in the video) were addressed and the forms used to present and study the mathematical ideas. If the video was related to an informal (or unintentionally educational) task, the group reported: any explicit or implicit involvement of mathematical ideas, how they were incorporated and how they were represented and communicated.

The groups were asked to:

- consider if there were noticeable differences in how the individuals in formal settings communicated and represented mathematical ideas as compared with those engaged in informal or unintentional educational tasks;

- compare the resources used in the video to determine whether they were used in common, effective, surprising or appropriate ways and to note any affordances or drawbacks from the incorporation of technological, digital or other resources;

- evaluate each video in relation to whether they would ever use this video with a class or if there were anything shown that they might want to adapt and adopt in their mathematics instruction. 
Of the 54 videos, the groups all identified the same 11 as unrelated to instructional or educational settings. These included a late-night talk-show reenactment of the game; a parent quizzing her child, who was dressed as an Angry Bird, about arithmetic facts; adolescents using graphing calculators to play homemade versions of the game; friends (most often children), family members or, in one case, a church youth group playing an embodied version of the game with physical toys outside of a school setting.

The members of the three groups then re-read their individual notes, summarized descriptions and the compiled spreadsheet information for the remaining 43 videos to see if any overarching ideas or themes emerged. They recorded such themes and then looked for evidence that supported them. If they could not support a theme with either a number of instances or a particularly in-your-facehard-to-miss occurrence, then they reframed, combined or, at times, eliminated themes. Based on the final themes, each group wrote a report.

The doctoral students then met over a period of 3 weeks to revisit the documentation each group had compiled (including its final report) in light of the research questions. They created a common spreadsheet that reflected key ideas that had arisen from each of the three groups and then submitted a compiled report.

\section{Discussion of Findings}

Some of the settings, such as the youth ministry group and the late night talk show, involved the game purely for entertainment purposes. In these instances, the incorporation of mathematics was impractical. However, when adults and children played physical versions of the game (outside of a formal educational setting), there were often squandered opportunities for informal learning through play. If the adults had incorporated measurement, connected mathematical language with physical action (e.g., "try increasing the angle for your launch") or explained relationships (e.g., how changes in the launch angle had an impact on the bird's flight trajectory), the tasks could have been more mathematically educational. We now turn to the 43 videos that appeared to be related to instruction.

\section{Mathematical Topics Addressed}

The videos analyzed dealt with a number of mathematics topics. As displayed in Table 1, the three most commonly verbalized mathematical terms were:

(a) parabola, which was occasionally introduced with accompanying gestural references to the bird's flight path (e.g., "the figure formed by the trajectory of the birds");

(b) angle, which almost always referred to the angle of projection (i.e., the launch angle), although it was rarely referred to in terms of either, and only in some cases was gesturing used to direct students' attention to this angle; 
Table 1 Frequency distribution of mathematical topics in videos

Mathematical topic

Frequency of appearance

(number of videos in which the topic appeared)

Parabola, as the general shape of the trajectory 16

Angle, in all but one case this was the angle of projection 12

Quadratic equation, as the function that models parabolas 10

Parabolic graphs, usually featuring either the vertices 9 or intercepts of these graphs

Velocity/speed, of the bird during flight 9

General Cartesian graphing, including axes, origin, 7 ordered pairs

Distance, either how to measure or calculate it based on 6 the location of two points

Angle measure, always using degrees as units 5

Geometric shapes, both in two and three dimensions 4

Maximum, as related to height or distance 4

Acceleration, as related to the bird in flight 3

Function, where distance was the output related to inputs 3 of either time or angle

Domain/range, of function 2

Integration/differentiation, always as related to distance, 2 velocity, or acceleration

Arc length 1

Arithmetic, including counting and simple addition $\quad 1$

Conversion of units, for linear distance $\quad 1$

Modeling, of a physical situation $\quad 1$

Slope, related to the tangent at a curve 1

Symmetry, the parabola's line of symmetry that goes $\quad 1$ through the vertex

Transformation, stretch and shift of a parabola in terms of 1 the equation $\mathrm{y}=a(x-h)^{2}+k$

(c) quadratic equation, which was always accompanied by representations in the algebraic register and introduced either as an equation that generates all parabolas or as an equation that models the trajectory of the birds in the game. ${ }^{2}$

Results suggest that instructors recognize the potential of Angry Birds as a resource to explore ideas that relate to quadratic functions, both in the algebraic and in the graphical registers. An argument could be made that the game offers a natural pre-structuring for such concepts. Instructors who focused solely on the graphical representation provided by the game (without any use of the algebraic register) tended to be very general in their

\footnotetext{
${ }^{2}$ Without access to the game's code, it is unclear whether the trajectory generated by the video game is a parabola or not, which raises interesting questions in relation to the notion of 'modeling' trajectories in the game by quadratic functions, questions that are not present for more 'natural' phenomena (e.g., the paths of water fountains).
} 
comments. These instructors often described the flight path shape as a parabola, and the few who discussed the symmetry of the parabola or the fact that it has a maximum were more likely to direct students' attention using either physical or cursor gesturing.

Before continuing with the remainder of the article, which is peppered with representative examples to provide the reader with a general sense of how the game was used in the teaching and learning of mathematics, there were two videos that used the game in singular ways not seen in any of the other videos. In the first instance, a student traced a bird's trajectory then erased the most curved part of the parabolic trajectory (near the vertex), replacing it with two intersecting straight segments to form an angle composed of two segments that extended the most linear parts of the initial and final descent of the trajectory. The student traced this angle onto a sheet of paper and then measured it as outlined in various video screen shots in Fig. 1, in effect using an angle to measure the spread of the parabola. It appeared that the student had been assigned an instructional task related to angles that was to incorporate the Angry Birds game. One can only wonder if this were not an instance of a double catachresis where: (a) the instructor was using a game designed for entertainment as a tool for mathematical learning, and (b) the student, rather than using the launch angle (as possibly envisioned by the instructor) to consider fitting a parabolic trajectory, instead created a central angle to consider the spread of a shape that, to the student, seemed to be an angle with some curvature.

In the second instance, an instructor used the game theme to have students launch physical rockets to simulate the birds' trajectories. Rather than using the digital environment as the interface platform, he relied on the students' understanding of the game, which involves aiming a projectile at a target, and then made connections by having students gather physical data in tables based on the flight of their own rocket launches. The video consisted of the instructor explaining the mathematics behind the

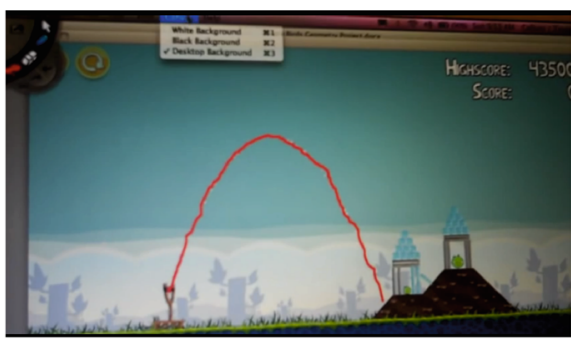

a

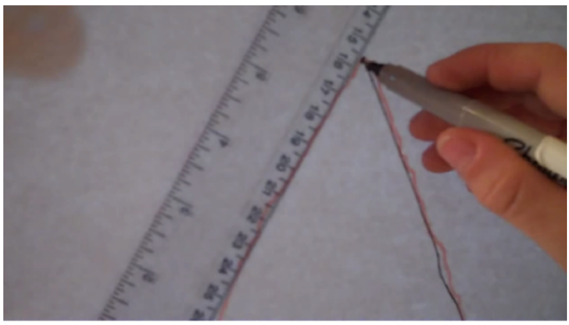

C

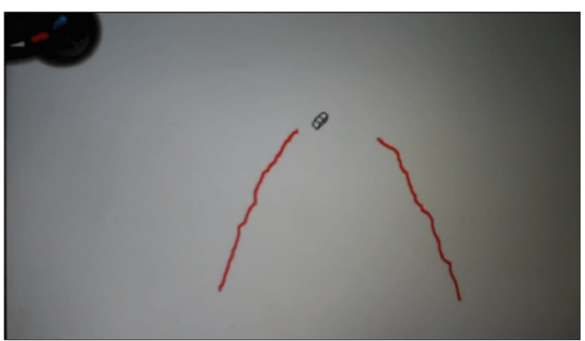

b

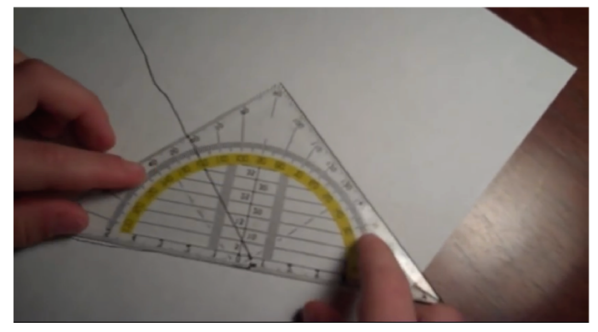

d

Fig. 1 a, b, c and d. An interesting interpretation of finding the angle of the bird's trajectory 
findings of the rocket launches, connecting it to the embodied physical experiment. The instructor clearly stated his objective as he lectured about the mathematics, making connections among the different registers of representation and between the mathematics and the flight of the rocket.

There was minimal use of digital tools in this video: however, the video game is what had been used to introduce the physical model, where launching rockets were physically modeling the digital Angry Birds game, which in turn connected to the mathematical equations and tables that mathematically modeled the rocket simulation (see also footnote 2). This video in particular prompted the research team to consider that instructors might have limited knowledge related to the specifics of the game or how to manipulate a digital environment in order to overlay text or other images on top of the game, but even so they still might be able to build connections to students' digital experiences.

Table 1 shows the mathematical topics addressed in the 43 videos. Some videos addressed more than one of the topics listed, while others integrated science and mathematics concepts. The most common science concepts noted were force, gravity, mass and resistance.

Most of the videos addressed secondary mathematics topics related to parabolic motion and appeared to be created by instructors or students at the middle school, high school or college level. There were, however, some notable exceptions, instances in which the instructors seemed to be incorporating the game not for its pre-structuring of certain mathematical concepts, but rather as a means to take iconic symbols from popular culture to motivate students. The first example of this was a video created by an elementary math instructor to show other instructors a physical game he had created. As displayed in Fig. 2 below, brightly wrapped containers were assigned numbers, and students were separated in four rotating groups to:

- throw the birds (plush toys);

- build the tower;

- sweep away any fallen containers after each throw;

- $\quad$ sort the containers based on their values.

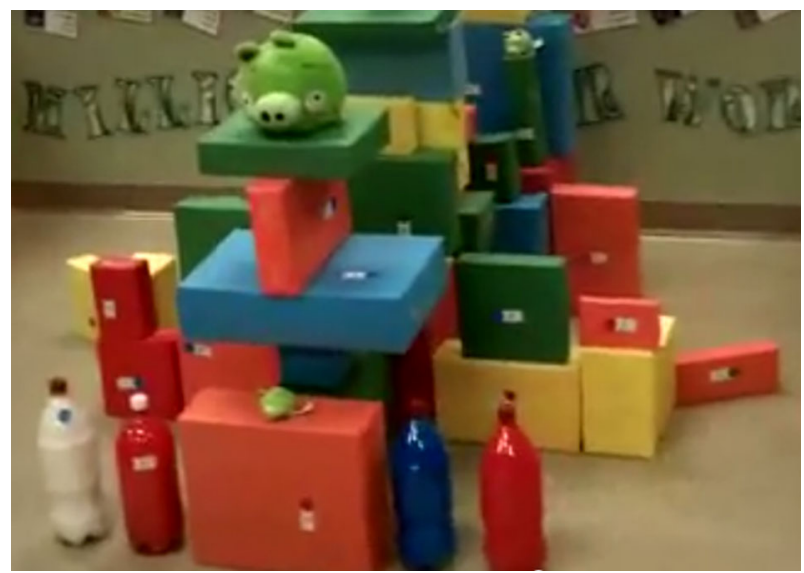

Fig. 2 Toss game for elementary students to practice addition 
After each toss, the whole class counted the containers and added to find the total points scored.

In the second episode, it was not entirely clear if the instructor were teaching an art or a math lesson, and the age of the students was not obvious (although the impression was of upper elementary school). In it, an instructor was shown naming and then drawing basic two-dimensional shapes to sketch an Angry Bird (see Fig. 3 below).

\section{Effective Incorporation of the Game}

While the three groups were not given a definition of what it meant to be effective, their results were strikingly similar in how they classified the videos. The videos labeled 'effective' by the three groups used the game in ways that there were explicit connections between the mathematics and the digital game. Upon re-inspection of all of the 'effective' videos, at least one of the following two themes was identified: (a) relevant connections and (b) multiple representations.

Relevant connections referred to the extent to which instructors were both modeling the use of and steering students to make either extra-mathematical connections between the digital and mathematical contexts or intra-mathematical connections between different mathematical concepts (Hoyles 2001). Multiple representations involved consideration of the semiotic resources used and the connections made by instructors among different registers of representation. Below, we illustrate practices that were judged 'effective' by relating details of how the Angry Birds game was used.

\section{Relevant Connections}

Addressing the first theme, several videos depicted instructors and students incorporating the game in a such way that its use capitalized on the mathematical elements prestructured by the scenario in the game (e.g., finding of intercepts for a quadratic equation that models the bird's flight trajectory). There was a good fit between the potentialities of the game as a digital tool and the mathematical task at hand (Goodhue 1995). Instructors in these videos were noted for their efforts to guide the instrumental genesis process by means of straightforward, explicit connections between the mathematical ideas and the context provided by the game, often alternating between

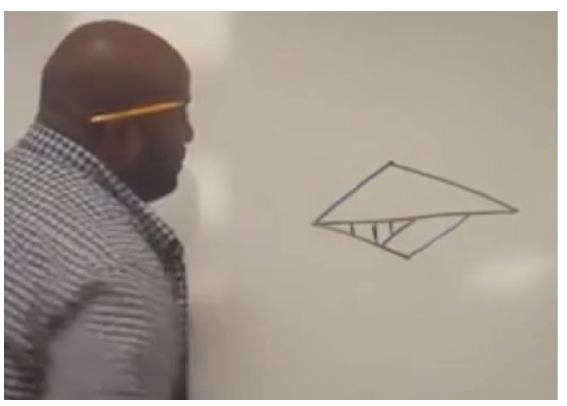

a

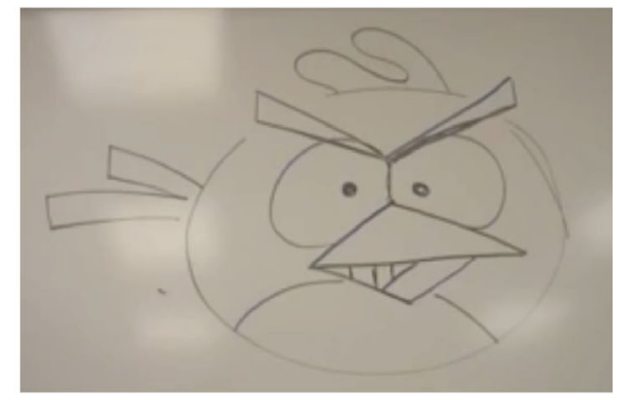

b

Fig. 3 a and b. Use of basic geometric shapes and art to draw an Angry Bird 
informal language typically used by game players (e.g., red bird, slingshot, pigs, blocks) and more formal mathematical language (e.g., parabola, roots of a quadratic equation, symmetry) used in mathematics classrooms.

A number of instructors used the game to provide a visual grounding for the mathematical ideas that were discussed. The game served as a context in which to engage in mathematical modeling. Yet, few actually took full advantage of the gaming context to apply the mathematical modeling in a way that improved students' performance in the game. For this reason, we consider both the static and dynamic ways in which relevant connections were made.

Static relevant connections were identified when instructors used the game solely as a visual backdrop, employing only screen shots of the game. Here the mathematics was a tool to model a particular aspect of the game. Instructors made explicit connections by referencing the trajectory of a bird that had been launched whose flight path was shown as a still image. The digital context was usually used to study a single parabola and its key features, with explicit links being made (both verbally and with gesturing) between the graphical and algebraic forms of a quadratic equation. In short, the 'school mathematics' overshadowed the game, and the opportunity to show mathematical optimization in action seemed lost.

In game-based instruction, instructors have the opportunity to contextualize learning so students are engaged using mathematical ideas in authentic ways to solve the challenges presented in the game (Watson and Fang 2012). In the dynamic relevant connections, instructors enriched instruction through contextualization (van Oers 1998, 2001) that involved actual game play with moving images. The mathematics was not only used as a means to model what occurred in the game; the mathematical ideas informed individuals about how to improve game performance. In these videos, by contrast, mathematically informed modifications were used to adjust the launch angle repeatedly in order to alter the bird's flight trajectory until the launched birds came closer to and eventually hit their targets. With static connections, the game was a digital tool to study the mathematics. With dynamic ones, this went a step further, using mathematical ideas as cognitive tools to address specific challenges introduced via the game's scenario through more direct interaction with the game (i.e., actual game play).

In one video that demonstrated static relevant connections, the instructor posted instructions on the board, shown in Fig. 4a, and kept them there through the entire lesson. He explained that the goal of the lesson was for students to use Angry Birds to

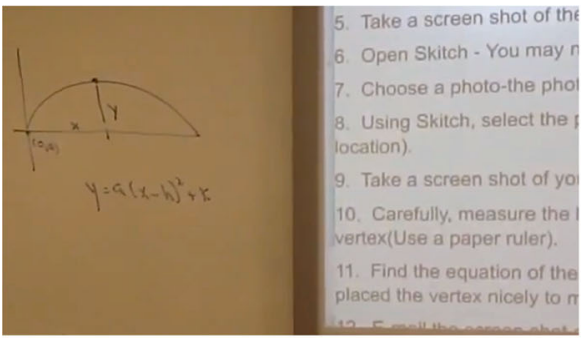

a

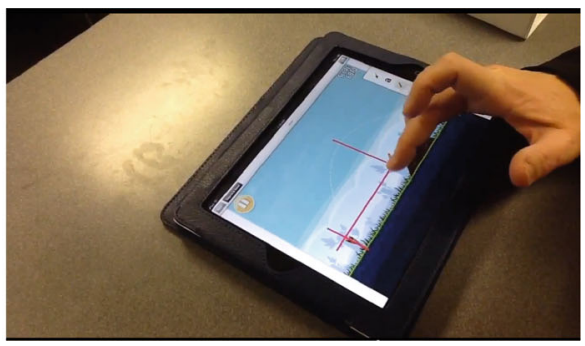

b

Fig. $4 \mathbf{a}$ and $\mathbf{b}$. List of instructions for students to use digital tools to determine the equation that models the bird's trajectory by first finding the parabola's vertex; working on the iPad to carry out the instructional task 
create parabolas on the class set of iPads. His explicit instructions guided students to measure the parabolas once the $x$ - and $y$-axes were drawn over the backdrop of the gaming environment, then to use software to preserve the screen shot and to draw in axes and a line of symmetry (see Fig. 4b). Students used rulers to measure the distances to the vertices of the parabolas. The students were then told to determine the parabolas' equations based on their findings. It appeared that the use of the iPads was part of standard classroom practice, so the operation of the technological device itself was not an added layer of complexity. So, for this task, students were using the digital game in co-ordination with other physical and digital tools. At the conclusion of the video, the instructor seemed to be moving about the room interacting with students individually, in order to address issues with the co-ordination of the game in relation to other tools and mathematical ideas.

Another video was identified for instrumental orchestration that deliberately started with static relevant connections before moving to dynamic ones. As displayed in Fig. 5, this instructor took a screen shot of a bird's trajectory in the game and imported it into presentation software. The instructor then used a variety of digital tools to make explicit connections to demonstrate how a parabola's intercepts can be used to determine an equation that models a given trajectory. Once the students learned how to find the equation for the parabola, they were to apply this process to improve their launches so as to win the game. This shift from static to dynamic was a deliberate, calculated move by the instructor. The video only displayed the front end of the instruction, stopping with the instructor's intentions for the task; it did not show any students engaging in the task. However, it was clear that the game was more than a digital instrument to study mathematical ideas; the mathematical concepts and processes were to fold back and become conceptual tools for students to use to improve game performance.

The video represented in Fig. $6 \mathrm{a}$ and $\mathrm{b}$ also displayed dynamic relevant connections. In this one, it as the instructor ${ }^{3}$ who played the game. Intermittently, while pausing it, he would insert text to explain the parabolic nature of the bird's flight path. He started with a trajectory model (Fig. 6a) that overshot the target. He then explained the parabola with overlaid axes, text and sliders (i.e., digital "knobs" that were moved along a horizontal continuum to adjust variables' quantities), so that he was able to adjust the trajectory in order for the bird to hit its target (Fig. 6b).

The instructors in all of these three videos did not simply use the game as a 'hook' for a lesson or as an anticipatory set to be abandoned once a more traditional lecture began. They incorporated the Angry Birds context throughout the video with clear tasks that intentionally helped students make connections between the mathematics and the game. In contrast to the instructors who used their digital skills to make relevant connections, there were also instances where individuals who seemed digitally savvy nevertheless failed to make either extra-mathematical or intra-mathematical connections. For example, in one video, the instructor demonstrated skill in using an interactive whiteboard and software tools to animate the writing and graphics on the board (as shown in Fig. 7), even color-coding equations by bird color. However, the mathematics was either verbalized or written without any explicit connections among the words, the

\footnotetext{
${ }^{3}$ The research team decided that this person was mostly likely an instructor, due to the nature of the video and the manner of the individual, although there was no explicit mention of 'students' or assigned 'tasks' during the video.
} 


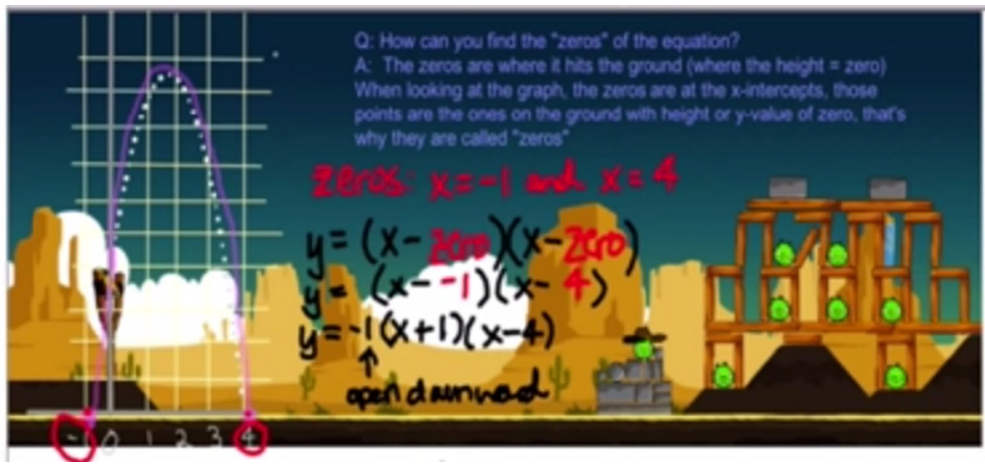

Fig. 5 Demonstration of how to model the bird's trajectory using information about the parabola's intercepts

algebraic equations (which were written but never explained), the points listed for the launch sites and the birds' trajectories. Each of the different registers used to represent ideas were treated as separate entities only linked implicitly by color. Even though the instructor emphasized the starting and landing locations of the birds, she failed to identify them as intercepts, a fact that impacted the equations modeling the birds' flight despite the fact that she had supplied all pertinent information. As Hoyles (2001) observes, "mathematical meanings derive from connections" (p. 34).

\section{Multiple Representations}

We now consider the second theme, multiple representations, using the same three videos previously described. As was the case depicted in Fig. 5, Fig. 6a and b reflect the instructor directly addressing how a deeper understanding of the mathematical context and concepts in turn folded back to have an impact on the playing of the game. However, there was a notable difference between the two videos. While it was obvious that the instructor in the Fig. 6 video was using the equation $y=a(x-h)^{2}+k$, this video did not show it. The instructor was relying on implicit connections between the different mathematical representations while making explicit the extra-mathematical connections between the mathematics and the context of the game. His ignoring of the intra-mathematical connections was in sharp contrast to the instructor in the Fig. 5 video who deliberately used both implicit and explicit semiotic clues to help students make connections (e.g., placing mathematical terms in quotation marks; placing the word "zero" in the equation, using color to make connections across registers) between

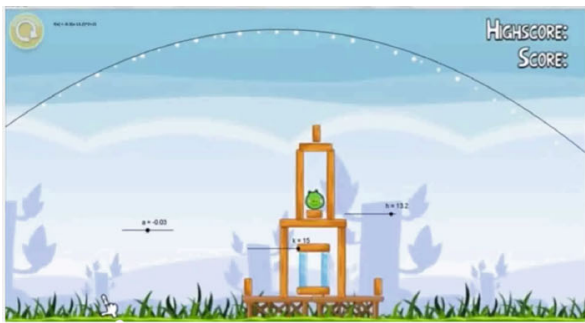

a

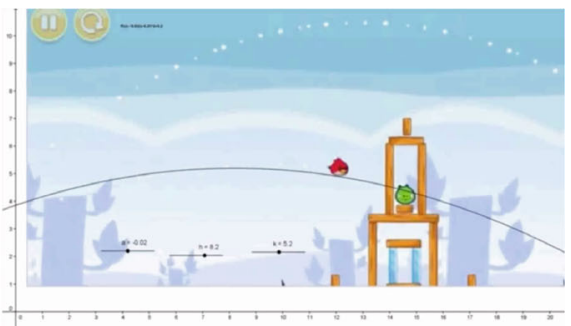

$\mathrm{b}$

Fig. $6 \mathbf{a}$ and $\mathbf{b}$. Use of sliders to adjust parameters to refine the trajectory of the bird to hit its target 


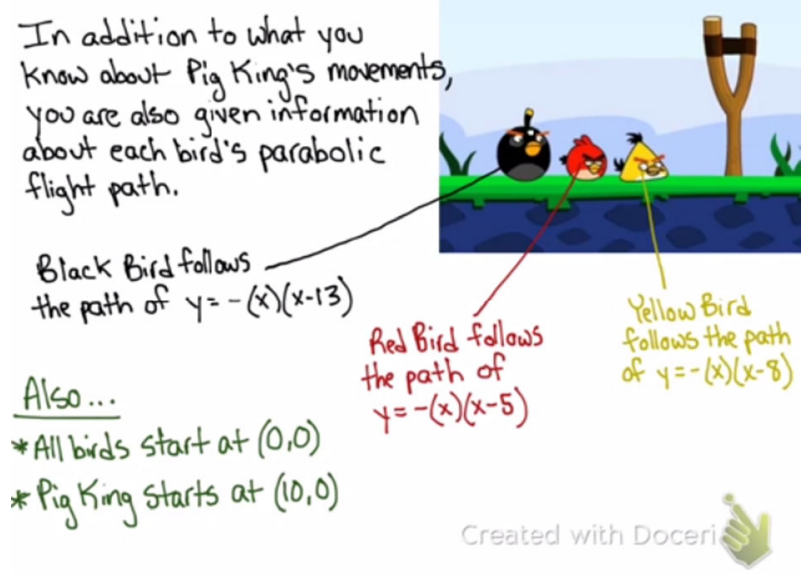

Fig. 7 Use of text, equations and color but without verbalized, explicit connections between the graphical and algebraic representations of the quadratic function

mathematical representations and concepts. It is also in contrast to the instructor in the video shown in Fig. $4 \mathrm{a}$ and $\mathrm{b}$ who made explicit connections between the algebraic and graphical representations of the quadratic equation, by clearly showing the $x$ - and $y$ coordinates of the parabola's vertex were represented by point $(h, k)$ in $y=a(x-h)^{2}+k$.

Addressing the second theme, multiple representations, the research team felt the most exemplary uses of Angry Birds included straightforward, explicit connections among the algebraic, graphical, written and verbal representations of the concepts in the lesson. Often, multiple representations were visible to the students throughout the lesson, as can be seen in examples from two separate videos (see Fig. 8a and b). Instructors deemed 'effective' with respect to this theme referred back to verbal or graphical representations continually while working with algebraic representations. They reinforced not only the connections among the numerous ways that mathematical concepts are represented, but also often pointed out the specific affordances of different representations. Moreover, the instructors who pointed out representational links to the same mathematical concept also seemed to place a greater emphasis on verbalizing connections between mathematical concepts.

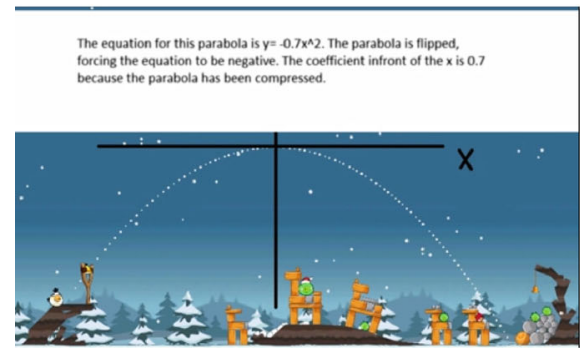

a

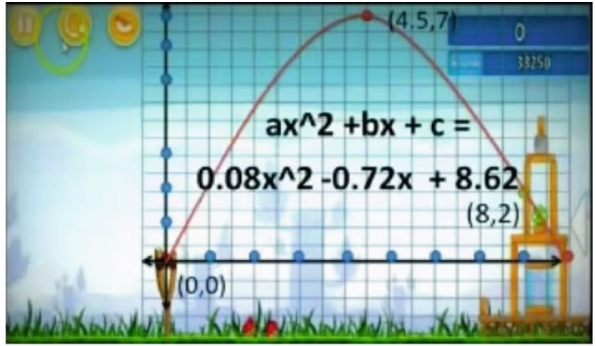

$\mathrm{b}$

Fig. 8 a and b. Examples from two instructors who used digital resources to connect algebraic and geometric representations of parabolas 
Some of the instructors in the videos were able to use a variety of presentation, recording and screen-capture software to present the mathematical content in various forms. They often superimposed axes or a grid over the screen shot to show how the parabola fits the bird's path. In fact, other individuals (presumably students), who perhaps did not have access to digital tools at home, were still able to make explicit connections in meaningful ways with 'low-tech' representations of the game (as displayed in Fig. 9), supplemented by explicit, verbalized connections (heard on the clip's audio).

\section{Ineffective Incorporation of the Game}

Three themes were identified regarding those videos deemed to have 'ineffective' incorporation of the video game: (a) ornamental add-on; (b) instructors' lack of resource mastery (at even a basic level); (c) students' lack of mathematical terminology/connections in Angry Birds projects for mathematics classes.

\section{Ornamental Add-On}

Incorporation of any tool (whether it be physical or digital) should do more than entertain students; it should influence how they come to understand mathematical ideas by creating a more connected, meaningful, contextualized lesson. The first theme, ornamental add-on, involved instructors who incorporated the digital game, but it remained solely an artifact, due to an absence of clear ties between the game and the mathematics at hand (i.e., the presumed main objective of the lesson). In some of the videos, the incorporation of the game actually became a distraction in class, as the instructor tried to move from some introduction of the game to the mathematical lesson without relevant connections between the two.

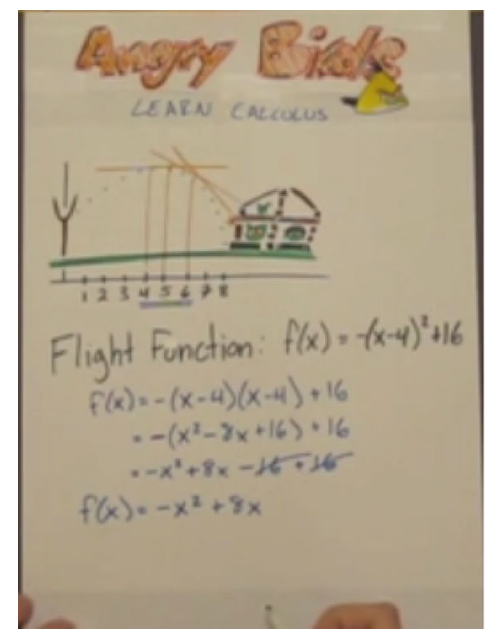

a

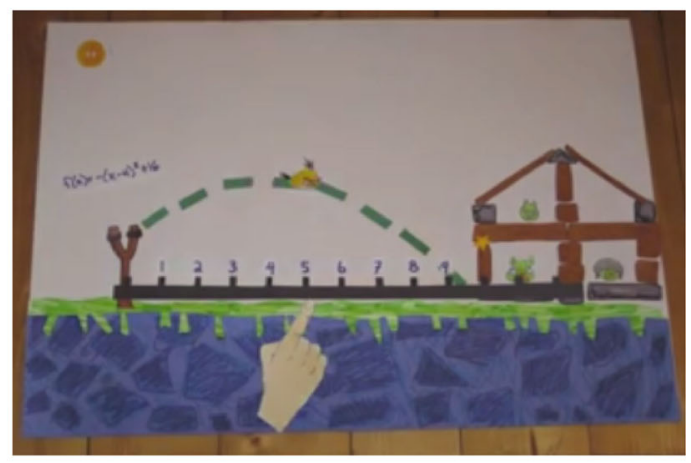

b

Fig. 9 a and b. Low-tech means created by students to represent the game 
Individuals in a number of videos made no connection, or at best a very forced one, between the game and a mathematical objective. For example, in one video an instructor demonstrated the game merely as a means to start a rather traditional lesson on measurement that focused on unit conversion between inches and feet; however, she never went back to associate the unit conversion with anything related to the game. In more than one video, instructors either inquired who had played the game or simply mentioned that the game involved angles as a segue into a lesson on angles. However, they failed to capitalize on the potential of the digital tool and did nothing to contextualize the lessons in the scenario of the game. For example, they never revisited how the measure of the angles of inclination at which birds in the game are launched actually influences the birds' flight trajectories and, hence, the play of the game.

In other cases, the instructor (or a selected student) would play the game without any scaffolding that might focus attention upon a certain aspect of the game. The instructor would then begin a traditional lecture, which usually involved quadratic equations, without any connections being made between a bird's flight trajectory and the mathematical topic of the day. In another video, an instructor did show how the trajectories of the birds can be modeled by parabolic graphs that are influenced by the angle of the slingshot release, but failed to point out the physical representation and meaning of the intercepts of the parabola, even though the lesson that immediately followed was on the roots of a quadratic equation. Such squandered opportunities for connections to the mathematical topics at hand happened in videos where the game could have provided an opportunity to enhance students' mathematical understanding in a way that would have been meaningful from the context of the game.

In these videos, use of the video game seemed to add little or no educational value in the lesson, since it failed to capitalize on the specific features and mathematical relationships involved in the game itself. As outlined by Grandgenett (2008), instructors must have a thorough understanding of how to teach the lesson using digital tools and be able to connect the tools incorporated directly to the content. The instructors in the ornamental add-on videos showed no signs of instrumental orchestration, even though most of them seemed to understand the game and how it worked, just as they appeared to understand the mathematical potential that the game held. In these videos, the connections between the game and the mathematical ideas were left to the students to make on their own. The instructors failed to support or direct the instructional genesis process - and the Angry Birds game never became more than an artifact from popular culture used as a hook to catch student attention.

\section{Instructors' Lack of Resource Mastery}

This second theme involved instructors using the digital game apparently without accurate knowledge of how to play it. For example, in one video, an instructor attempted to give a lesson on parabolas using a Smart Board. She used the game as a backdrop and drew an $x$-axis at ground level and a $y$-axis where the catapult stands, but then was unable to launch a bird. She struggled with this to the point of getting knocked out of the gaming screen entirely, until she finally drew in a parabola and told the students in the classroom to "pretend this was the flight of my bird". It was surprising to us that there were videos in which the instructors did not seem confident with the digital game itself. Even when the instructor understood the content and how the game 
could be used as a tool for learning of the mathematics, the instructors' lack of digital skill led to lessons and tasks that were not enhanced by the game due to their basic inability to operate the tool (i.e., play the game) themselves. It is important to note that the addition of a digital resource brings with it a new layer of complexity to the classroom (Hoyles et al. 2004), both for instructors and for students. Even with deliberate planning and organization, instructors cannot possibly facilitate instrumental genesis using digital artifacts they themselves are unable to use as tools.

\section{Students' Lack of Mathematical Terminology/Connections}

This third (and final) theme was only noted in videos that had been created by students. These videos showed that students often fail to incorporate meaningful mathematical content and terminology when given project assignments that draw on the Angry Birds gaming environment. The most common examples of videos of this nature were student created and had obviously been submitted as math projects (detectable either by their titles or by the dialogue in the video) in which they had produced some kind of physical model to recreate the game. While many students were enacting the game, there was a distinct absence of mathematical terminology, including even a lack of words with mathematical meaning that are common in everyday parlance. Instead of using the word 'angle', for instance, the video creators would say "it goes up"; instead of using the word 'curve' or 'parabola', the video creators would refer to "where the bird flew" or "the bird's path". In another example, the student creator of one video used Angry Birds in order to create a parabola from the path of the bird as shown in Fig. 10a and b However, no information was given on how points were measured to arrive at the graph on a standard set of axes, nor anything on what to do once particular points on the graph were used to sketch a curve of a parabola. Instead, the video abruptly jumps from Fig. 10a to $\mathrm{b}$ without any video or audio transition.

The end goal of the assignment seemed to be to identify a certain number of points and use them to curve sketch; however, the abrupt jump without any information on how values were assigned to the ordered pairs in the context of the landscape of the gaming environment made one question whether the points shown in Fig. 10b actually model the trajectory shown in Fig. 10a. Even though some of the student project videos

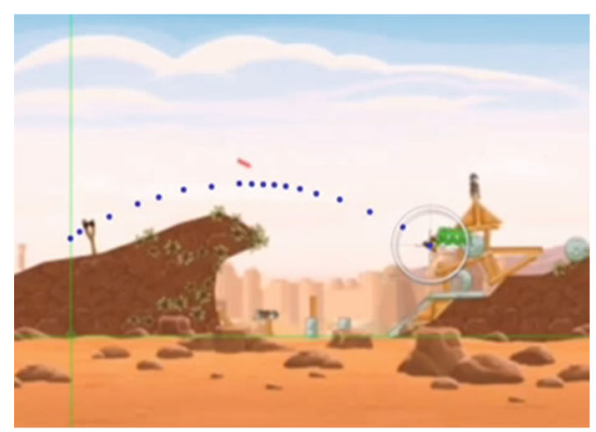

a

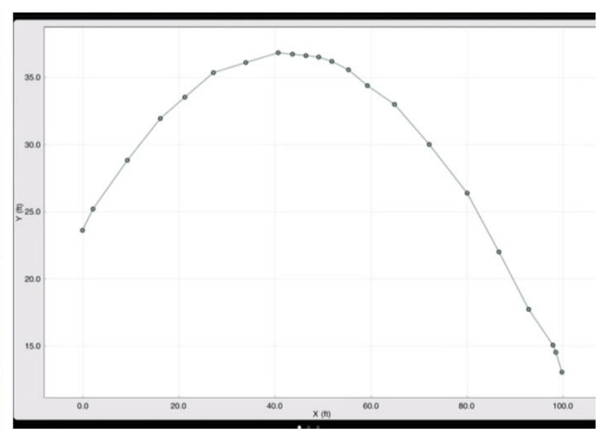

b

Fig. 10 a and b. Student project to map a bird's flight trajectory without any verbalized connections between the game and the mathematical model 
(such as the one from which Fig. 9 was taken) did make direct mathematical connections between representations in different registers, there were several others in which students were using technology to record themselves using the digital or physical adaptation of the Angry Birds game in a manner that neither incorporated mathematical content in a meaningful way nor in a way that demonstrated they had made connections between the context of the game and the mathematical topics addressed. What is not clear from the data we analyzed is whether the failure to make relevant connections was more a function of the lack of understanding of the students who created the videos or more a failure in terms of the instructional guidelines that prompted the videos. However, it might suggest that the instructors either accepted a lack of explicit connections as normative for students or that they themselves were failing to model explicit extra- and intra-mathematical connections in their instruction.

\section{Some Implications}

According to Grandgenett (2008), one of the fundamental qualities of instructors with strong Technological Pedagogical Content Knowledge (Mishra and Koehler 2006) is that they can focus effectively on the mathematical concepts of the lesson while taking advantage of the integration of digital tools. They understand that the digital tool selected must fit the task at hand. They stay on task irrespective of the digital tools that are being incorporated by having clear objectives and outcomes that play out in explicit connection between the digital tool and the mathematical ideas, as well as among the different registers used to represent of the mathematics.

Laborde (2001) classified a range of approaches taken by instructors when using dynamic digital tools; the least common approaches involved instructional tasks that depended on, as well as took meaning from, the tools they used. As was seen in some of the videos, use of Angry Birds can facilitate a (formerly paper-and-pencil only) mathematical task by making it more interesting or, perhaps, easier to visualize. However, it was also noted that the game can go beyond this and serve as a tool that drives the task. This type of incorporation, where the mathematical information was used to improve game play, seems to illustrate the "engaging and imaginative mathematics instructors for today's world" (p. 158) that Grandgenett (2008) mentions.

In addition, we see three broad implications for incorporating the Angry Birds game into mathematics instruction. The first is that instructors need to reconsider what constitute 'real-world' applications and their role in the teaching of mathematics to include common student digital experiences. Due to the particular launching trajectories that occur in Angry Birds, there are certain mathematical topics for which this tool is well suited. However, for the game to move from an artifact introduced for entertainment or motivational reasons to an instrument that can shape how students understand particular concepts (and the way they view mathematics in general) depends on the careful planning and organization of the instructor.

While the game is a virtual product of a digital environment, such video games have filtered into the lives of adolescents and might be much more 'real' in the students' worlds than other applications commonly seen for parabolic graphs and quadratic equations that involve scenarios unfamiliar to students, such as shooting cannon balls. Despite the fact that Angry Birds might be a good fit for certain mathematical topics, 
and that many students are familiar with this particular game, this does not nullify in any way the requirement that instructors must understand the premises and functionality of the game if it is to be incorporated successfully into instruction. While the game itself might lend itself to certain topics, the instrumental genesis process must still be carefully orchestrated.

The second implication is that digital games (such as Angry Birds) can and should be more than ornamental add-ons when incorporated into mathematics classrooms. They often bring with them a wealth of modeling and optimization options that are underutilized, or even squandered, when they only act as anticipatory hooks to catch students' attention or when they are incorporated post hoc as 'rewards' after the theoretical, abstract mathematical ideas have been presented. Instead, digital games should serve as contextualized experiences that not only relate to mathematical concepts and relationships directly, but also provide instructors with a means to show how mathematics can be used for modeling and improvement. These digital experiences should be aligned directly with the objectives of the lesson in ways that demonstrate how modeling can be used to help students understand mathematical concepts and relationships better, as well as those situations that are encountered in digital environments. If a game is only used to provide a static visual grounding, then any game-based motivation is overshadowed by 'school mathematics' and opportunities for instructors to show the power of mathematics and how mathematical ideas can be themselves powerful tools to help solve tasks (like those that arise in digital gaming environments) are squandered. In these instances, the game is nothing more that a digital manipulative devoid of the motivation that the gaming scenario might provide.

The third, and final, implication is that effective use of digital tools in mathematical instruction needs to be done in a deliberate, co-ordinated manner. Students should not be expected simply to play a game or engage with a digital resource and discover hidden mathematical content. Instrumental orchestration suggests that instructors must carefully plan tasks and scaffold instruction to demonstrate both extra- and intramathematical connections. Mathematics ideas should be framed through the relationships among the context of the digital game, the digital interface of the user, the platform for the game and the mathematical content. The most effective incorporation of digital games seems to occur when there is a coherent effort on the part of an instructor to make explicit, relevant connections not only between the game as a digital interface tool and the mathematics, but also between the context of the game and mathematical ideas using a variety of mathematical representations. Rather than simply getting students' attention by claiming (based on whatever evidence) that the trajectories in Angry Birds are parabolas, students should be immersed in the topic, exploring how equations can be used to solve problems presented in the game by constructing coordinate grids and mathematical equations that model the bird's motion to improve results based on various launch angles (e.g., Lamb 2013).

The importance of integrating the mathematics and the digital game is not just limited to classroom teaching. Instructors must carefully design such instructional tasks so digital games can be applied in ways that students are able to make connections with the mathematical concepts while completing outside assignments. One thing that became clear in this study is that careful, deliberate co-ordination between the digital environment and mathematical ideas also applies to student projects assigned as homework. Without carefully crafted instructions and explicit expectations, students 
left on their own may not make the connections between a game and the intended mathematical ideas and terminology. If the instructors do not anticipate student misconceptions or properly prepare students for digital media use, then it is likely that students will focus only on the entertainment aspect of their experience and completely miss the mathematical objective of the task.

\section{Appendix}

Table 2 Data set of URLs for videos used in the study

URLs for YouTube Videos included in Data Set

1. http://www.youtube.com/watch?v=m44DtKkpEac

2. http://www.youtube.com/watch?v=D8Kbdce0Zrg

3. http://www.youtube.com/watch? $\mathrm{v}=\mathrm{eBOB} I \mathrm{IvLXRE}$

4. http://www.youtube.com/watch?v=FiUuzkBwtGA

5. https://www.youtube.com/watch?v=H8YBiJF62Us

6. https://www.youtube.com/watch?v=JEE4g_MHycA

7. https://www.youtube.com/watch? $\mathrm{v}=\mathrm{P} 3 \mathrm{qsHbTazGs}$

8. https://www.youtube.com/watch? $\mathrm{v}=\mathrm{xSpk}$ 8OWCLGs

9. http://www.youtube.com/watch? $\mathrm{v}=\mathrm{pZdibqdrFbo}$

10. http://www.youtube.com/watch?v=DM76uN3IXJQ

11. http://www.youtube.com/watch? $\mathrm{v}=\mathrm{X}-\mathrm{mXg} 9 \mathrm{MTTW} 0$

12. http://www.youtube.com/watch? $v=8$ hFbxPKTg-c

13. http://www.youtube.com/watch? $v=$ f43EvBIZTMo

14. http://www.youtube.com/watch?v=bsYLPIXI7VQ

15. http://www.youtube.com/watch?v=1S1wMAfsGTo

16. http://www.youtube.com/watch? $\mathrm{v}=\mathrm{j} 79 t 05 \mathrm{Dqv} 9 \mathrm{U}$

17. http://www.youtube.com/watch? v=NcZi0MTmfnQ

18. https://www.youtube.com/watch?v=KPnnDa0CTXI

19. http://www.youtube.com/watch? $\mathrm{v}=\mathrm{jqN} 4 \mathrm{xofBDA} 8$

20. http://www.youtube.com/watch? $\mathrm{v}=\mathrm{i} \_$CswIQCKNs

21. http://www.youtube.com/watch?v=JUcyOM0Zg0c

22. http://www.youtube.com/watch? $\mathrm{v}=$ samMCDoSbWg

23. http://www.youtube.com/watch? v=FWHH_P971Z8

24. http://www.youtube.com/watch?v=hWvQeb7YsEQ

25. http://www.youtube.com/watch?v=SqgMHKoVdW0

26. http://www.youtube.com/watch?v=ubew8X8ZKO4

27. http://www.youtube.com/watch? $\mathrm{v}=\mathrm{taV04KCfPxQ}$

28. http://www.youtube.com/watch?v=5WON7AHBaqY

29. http://www.youtube.com/watch? $v=$ rudBfD_J3kg

30. http://www.youtube.com/watch?v=EUrMI0DIh40 
Table 2 (continued)

URLs for YouTube Videos included in Data Set

31. http://www.youtube.com/watch? $\mathrm{v}=\mathrm{O}-\mathrm{KMkWOuC9w}$

32. http://www.youtube.com/watch?v=cSYB6ZQNe4Y

33. http://www.youtube.com/watch? $=$ $=\mathrm{kOBiEMs6nGM}$

34. http://www.youtube.com/watch?v=63BXVRXz-w4

35. http://www.youtube.com/watch? $\mathrm{v}=\mathrm{NQ}-46 \mathrm{YyZC} 4 \mathrm{I}$

36. http://www.youtube.com/watch?v=p8Ljzl631Uk

37. http://www.youtube.com/watch?v=peYroZmlDm0

38. http://www.youtube.com/watch? $=$ nLK9mCpwYqA

39. http://www.youtube.com/watch?v=MM3ubWkKZkM

40. http://www.youtube.com/watch?v=NnW1yMNeAH8

41. http://www.youtube.com/watch?v=zgRBPubt_ik

42. http://www.youtube.com/watch?v=75kSXTkRKgE

43. http://www.youtube.com/watch? $=$ =ZP4-LiwZFKA

44. http://www.youtube.com/watch?v=sU_TAeWf6ko

45. http://www.youtube.com/watch?v=n4tWXypvhmk

46. http://www.youtube.com/watch? $=\mathrm{Q} 4 \mathrm{xLDYfVryo}$

47. http://www.youtube.com/watch?v=VSH4jreqZ6g

48. http://www.youtube.com/watch? $v=$ fnvPvulrACM

49. http://www.youtube.com/watch?v=B-uvd7FLr_s

50. http://www.youtube.com/watch?v=VOGsXX5xNfI

51. http://www.youtube.com/watch?v=b9X-E4FXbi4

52. http://www.youtube.com/watch?v=kcYp4Tlv46s

53. http://www.youtube.com/watch?v=62KqMwBNYSA

54. http://www.youtube.com/watch?v=d6f3K0Gw0zI

\section{References}

Alagic, M. (2003). Technology in the mathematics classroom: conceptual orientation. Journal of Computers in Mathematics and Science Teaching, 22(4), 381-399.

Ball, L., \& Stacey, K. (2005). Teaching strategies for developing judicious technology use. In W. Masalski \& P. Elliott (Eds.), Technology-supported mathematics learning environments (pp. 3-15). Reston: National Council of Teachers of Mathematics.

Bourgonjon, J., Valcke, M., Soetaert, R., \& Schellens, T. (2010). Students' perceptions about the use of video games in the classroom. Computers \& Education, 54(4), 1145-1156.

Boyan, A., \& Sherry, J. (2011). The challenge in creating games for education: aligning mental models with game models. Child Development Perspectives, 5(2), 82-87.

Bragg, L. (2007). Students' conflicting attitudes towards games as a vehicle for learning mathematics: a methodological dilemma. Mathematics Education Research Journal, 19(1), 29-44.

Chen, R. (2011). Preservice mathematics teachers' ambiguous views of technology. School Science and Mathematics, 111(2), 56-67.

Clark, R. (1983). Reconsidering research on learning from media. Review of Educational Research, 53(4), 445-459. 
Clark-Wilson, A., Robutti, O., \& Sinclair, N. (Eds.). (2014). The mathematics teacher in the digital era: An international perspective on technology-focused professional development. Berlin: Springer.

de Freitas, S. (2006). Learning in immersive worlds: A review of game-based learning. [Electronic version] Retrieved December 2, 2014 from: http://www.jisc.ac.uk/media/documents/programmes/ elearninginnovation/gamingreport_v3.pdf

Devlin, K. (2011). Mathematics education for a new era: Video games as a medium for learning. Natick: A. K. Peters, Ltd.

Dewey, B., Singletary, T., \& Kinzel, M. (2009). Graphing calculator use in algebra teaching. School Science and Mathematics, 109(7), 383-393.

Drickey, N. (2006). Learning technologies for enhancing student understanding of mathematics. International Journal of Learning, 13(5), 109-116.

Drijvers, P., Doorman, M., Boon, P., Reed, H., \& Gravemeijer, K. (2010). The teacher and the tool: instrumental orchestrations in the technology-rich mathematics classroom. Educational Studies in Mathematics, 75(2), 213-234.

Duval, R. (1999). Representation, vision and visualization: Cognitive functions in mathematical thinking. In F. Hitt and M. Santos (Eds.), Proceedings of the Twenty-first Annual Meeting of the North American Chapter of the International Group for the Psychology of Mathematics Education (Vol. 1, pp. 3-26). Mérida, MX: PME-NA.

Duval, R. (2006). A cognitive analysis of problems of comprehension in a learning of mathematics. Educational Studies in Mathematics, 61(1/2), 103-131.

Erhel, S., \& Jamet, E. (2013). Digital game-based learning: Impact of instructions and feedback on motivation and learning effectiveness. Computers \& Education, 67(1), 156-167.

Federation of American Scientists (2006). Harnessing the power of video games for learning [Electronic version] Retrieved January 14, 2015 from: http://www.fas.org/programs/ltp/policy_and_publications/ summit/Summit\%20on\%20Educational\%20Games.pdf

Gee, J. (2003). What video games have to teach us about learning and literacy. New York: Palgrave/ MacMillan.

Gillispie, L., Martin, F., \& Parker, M. (2010). Effects of a 3-D video game on middle school student achievement and attitude in mathematics. Electronic Journal of Mathematics and Technology, 4(1), 6880 .

Goodhue, D. (1995). Understanding user evaluations of information systems. Management Science, 41(12), 1827-1844.

Goodhue, D., \& Thompson, R. (1995). Task-technology fit and individual performance. MIS Quarterly, 19(2), 213-236.

Grandgenett, N. (2008). Perhaps a matter of imagination: TPCK in mathematics education. In AACTE Committee on Innovation and Technology (Ed.), Handbook of technological pedagogical content knowledge (TPCK) for educators (pp. 145-165). New York: Routledge.

Gros, B. (2007). Digital games in education: the design of games-based learning environments. Journal of Research on Technology in Education, 40(1), 23-38.

Gunter, G., Kenny, R., \& Vick, E. (2008). Taking educational games seriously: using the RETAIN model to design endogenous fantasy into standalone educational games. Educational Technology Research and Development, 56(5/6), 511-537.

Heid, K. (2005). Technology in mathematics education: Tapping into visions of the future. In W. Masalski \& P. Elliott (Eds.), Technology-supported mathematics learning environments (pp. 345-366). Reston: National Council of Teachers of Mathematics.

Heid, K., \& Edwards, M. (2001). Computer algebra systems: revolution or retrofit for today's mathematics classrooms? Theory Into Practice, 40(2), 128-136.

Hoopes, J. (Ed.). (1991). Peirce on signs. Writings on the semiotic by Charles Sanders Peirce. Chapel Hill: University of North Carolina Press.

Hoyles, C. (2001). Steering between skills and creativity: a role for the computer? For the Learning of Mathematics, 21(1), 33-39.

Hoyles, C., Noss, R., \& Kent, P. (2004). On the integration of digital technologies into mathematics classrooms. International Journal of Computers for Mathematical Learning, 9(3), 309-326.

Kafai, Y., Heeter, C., Denner, J., \& Sun, J. (Eds.). (2008). Beyond Barbie ${ }^{\circledR}$ and Mortal Kombat: New perspectives on gender and gaming. Cambridge: MIT Press.

Ke, F. (2009). A qualitative meta-analysis of computer games as learning tools. In R. Ferdig (Ed.), Handbook of research on effective electronic gaming in education (Vol. 1, pp. 1-32). Hershey: IGI-Global.

Kebritchi, M., Hirumi, A., \& Bai, H. (2010). The effects of modern mathematics computer games on mathematics achievement and class motivation. Computers \& Education, 55(2), 427-443. 
Ketelhut, D., \& Schifter, C. (2011). Teachers and game-based learning: improving understanding of how to increase efficacy of adoption. Computers \& Education, 56(2), 539-546.

Koehler, M., \& Mishra, P. (2005). Teachers learning technology by design. Journal of Computing in Teacher Education, 21(3), 94-102.

Laborde, C. (2001). Integration of technology in the design of geometry tasks with Cabri-Geometry. International Journal of Computers for Mathematical Learning, 6(3), 283-318.

Lamb, J. (2013). Angry birds mathematics: parabolas and vectors. The Mathematics Teacher, 107(5), 334 340 .

Lawrenz, F., Gravely, A., \& Ooms, A. (2006). Perceived helpfulness and amount of use of technology in science and mathematics classes at different grade levels. School Science and Mathematics, 106(3), 133139.

McDaniel, R., \& Kenny, R. (2013). Evaluating the relationship between cognitive style and pre-service teachers' preconceived notions about adopting console video games for use in future classrooms. International Journal of Game-Based Learning, 3(2), 55-76.

McGee, D., \& Martinez-Planell, R. (2014). A study of semiotic registers in the development of the definite integral of functions of two and three variables. International Journal of Science and Mathematics Education, 12(4), 883-916.

McGee, D., \& Moore-Russo, D. (2015). Impact of explicit presentation of slopes in three dimensions on students' understanding of derivatives in multivariable calculus. International Journal of Science and Mathematics Education, 13(2), 357-384.

Mishra, P., \& Koehler, M. (2006). Technological pedagogical content knowledge: a framework for teacher knowledge. Teachers College Record, 108(6), 1017-1054.

Moore-Russo, D., \& Viglietti, J. (2012). Using the $\mathrm{K}_{5}$ connected cognition diagram to analyze teachers' communication and understanding of regions in three-dimensional space. Journal of Mathematical Behavior, 31(2), 235-251.

Moreno-Armella, L., Hegedus, S. J., \& Kaput, J. J. (2008). From static to dynamic mathematics: historical and representational perspectives. Educational Studies in Mathematics, 68(2), 99-111.

NCTM. (2000). Principles and standards for school mathematics. Reston: National Council of Teachers of Mathematics.

Noss, R., \& Hoyles, C. (1996). Windows on mathematical meanings: Learning cultures and computers. Dordrecht: Kluwer Academic Publishers.

Núñez, R. E., Edwards, L. D., \& Matos, J. F. (1999). Embodied cognition as grounding for situatedness and context in mathematics education. Educational Studies in Mathematics, 39(1-3), 45-65.

Owston, R. (1997). The World Wide Web: a technology to enhance teaching and learning? Educational Researcher, 26(2), 27-33.

Ozel, S., Yetkiner, Z., \& Capraro, R. (2008). Technology in K-12 mathematics classrooms. School Science and Mathematics, 108(2), 80-85.

Pastore, R., \& Falvo, D. (2010). Video games in the classroom: pre- and in-service instructors' perceptions of games in the K-12 classroom. International Journal of Instructional Technology and Distance Learning, $7(12), 49-57$.

Prensky, M. (2001). Digital game-based learning. New York: McGraw-Hill.

Proctor, M., \& Marks, Y. (2013). A survey of exemplar teachers' perceptions, use, and access of computerbased games and technology for classroom instruction. Computers \& Education, 62(1), 171-180.

Rabardel, P. (1995). Les hommes et les technologies: Approche cognitive des instruments contemporains. Paris: Armand Colin.

Rabardel, P. (2001). Instrument-mediated activity in situations. In A. Blandford, J. Vanderdonckt, \& P. Gray (Eds.), People and computers $X V$-Interactions without frontiers (pp. 17-30). Berlin: Springer-Verlag.

Radford, L. (2002). The seen, the spoken and the written: A semiotic approach to the problem of objectification of mathematical knowledge. For the Learning of Mathematics, 14-23.

Radford, L., Bardini, C., Sabena, C., Diallo, P., \& Simbagoye, A. (2005). On embodiment, artifacts, and signs: A semiotic-cultural perspective on mathematical thinking. In Chick, H. L. \& Vincent, J. L. (Eds.), Proceedings of the 29th Conference of the International Group for the Psychology of Mathematics Education (Vol. 4, pp. 113-120). Melbourne, PME.

Sinclair, N., \& Crespo, S. (2006). Learning mathematics in dynamic computer environments. Teaching Children Mathematics, 12(9), 437-444.

Squire, K. (2006). From content to context: videogames as designed experience. Educational Researcher, $35(8), 19-29$.

Trouche, L. (2003). From artifact to instrument: mathematics teaching mediated by symbolic calculators. Interacting with Computers, 15(6), 783-800. 
Trouche, L. (2004). Managing the complexity of human/machine interactions in computerized learning environments: guiding students' command process through instrumental orchestrations. International Journal of Computers for Mathematical Learning, 9(3), 281-307.

Trouche, L. (2005). Instrumental genesis: Individual and social aspects. In D. Guin, K. Ruthven, \& L. Trouche (Eds.), The didactical challenge of symbolic calculators: Turning a computational device into a mathematical instrument (pp. 197-230). New York: Springer.

van Oers, B. (1998). The fallacy of decontextualization. Mind, Culture, and Activity, 5(2), 135-142.

van Oers, B. (2001). Contextualization for abstraction. Cognitive Science Quarterly, 1(3), 279-305.

Vogel, J., Vogel, D., Cannon-Bowers, J., Bowers, C., Muse, K., \& Wright, M. (2006). Computer gaming and interactive simulations for learning: a meta-analysis. Journal of Educational Computing Research, 34(3), 229-243.

Watson, W., \& Fang, J. (2012). PBL as a framework for implementing video games in the classroom. International Journal of Game-Based Learning, 2(1), 77-89. 